\title{
Natione Hispanus. Sobre la identificación de los hispanos en el Imperio romano
}

\section{Natione Hispanus. On the Identification of the Hispani in the Roman Empire}

\section{Pablo Ozcáriz Gil ${ }^{1}$}

\author{
Universidad Rey Juan Carlos/Universidad Pública de \\ Navarra (España)
}

ORCID: https://orcid.org/0000-0002-3390-4386

Recibido: 31-05-2021

Aceptado: 16-06-2021

\section{Resumen}

El objetivo de este artículo es poner de relieve que fue Roma la responsable de denominar Hispania al espacio geográfico que cuenta con los Pirineos y las costas mediterránea, atlántica y cantábrica como fronteras naturales. También de dotar a la palabra de una identidad propia. Este es el mismo término que a lo largo del tiempo evolucionó en tantos y tantos contextos históricos, administrativos, políticos y culturales y que terminó denominando a la España actual. El término fue asimilado por sus habitantes ya desde cronología republicana, independientemente de si eran nacidos en Corduba, en Emerita Augusta, en Lucus Augusti, en Tarraco, o cualquier otra pequeña localidad de sus respectivas provincias. Esta asimilación no fue idéntica en todas las escalas sociales, y evolucionó a lo largo del tiempo. Finalmente, se entra en detalle en la utilización de la fórmula natione Hispanus/a presente en la epigrafía romana.

Palabras-clave: Hispania, natione Hispanus, natione Hispana, identidad, alteridad, nación.

\footnotetext{
${ }^{1}$ (pablo.ozcariz@urjc.es) Profesor de Historia Antigua de la Universidad Rey Juan Carlos desde 2005, desde 2011 como Titular de Universidad. Licenciado en Historia Antigua por la Universidad de Navarra y Doctor en Historia Antigua por la Universidad de Barcelona. Académico correspondiente de la Real Academia de la Historia. Miembro de los grupos de investigación CEIPAC y HASTHGAR. Bibliografía destacada: "La datación del gobierno hispano de C. Asinius Gallus". Latomus: Revue d'études latines 76.4, 2017 pp. 1017-1030; "La administración de la provincia Hispania citerior durante el Alto Imperio. Organización territorial, cargos administrativos y fiscalidad". Colección Instrumenta 44 (Sello de Calidad Fecyt. Mención internacional), ed. Universitat de Barcelona, Barcelona 2013; Los conventus de la Hispania citerior. Ed. Dykinson-Servicio de Publicaciones de la URJC, Madrid, 2006).
} 


\begin{abstract}
The aim of this article is to highlight the fact that Rome was the responsible for naming with the word Hispania the geographical area that has the Pyrenees and the Mediterranean, Atlantic and Cantabrian coasts as its established borders. It was equally responsible for giving the word an identity of its own. This is the same term that evolved over time in so many historical, administrative, political and cultural contexts and ended up denominating present-day Spain. Its local inhabitants assimilated the term as early as Republican times, regardless of whether they were born in Corduba, Emerita Augusta, Lucus Augusti, Tarraco or any other small town in their respective provinces. This assimilation was not identical at all social levels, and evolved over time. Finally, the use of the formula natione Hispanus/a in roman epigraphy is examined in detail.
\end{abstract}

Keywords: Hispania, natione Hispanus, natione Hispana, identity, alterity, nation.

\title{
1. Los términos Iberia e Hispania
}

Según las fuentes escritas, fenicios y griegos fueron los primeros pueblos en tomar contacto con los habitantes de la península Ibérica. Los griegos denominaron a este territorio "Iberia". Otra zona situada en el confín oriental del mundo entonces conocido, en el Cáucaso, tenía el mismo nombre. Según Estrabón, esta coincidencia podría deberse a que en ambos lugares existían minas de oro (Str. 11, 2, 19). El nombre se debió utilizar en primer lugar para la Iberia oriental y, posteriormente, para la península Ibérica por extensión y simetría de ambos extremos del mundo (Domínguez Monedero 1983: 204ss.). Ambas Iberias eran lugares alejados del centro del mundo griego y míticos, perfectos para alojar historias fabulosas de los héroes viajeros y de tópicos sobre riquezas fantásticas. A ambos lugares, por ejemplo, llegó Herakles en el cumplimiento de las labores que le mandó Euristeo.

Desconocemos en qué momento los griegos fueron conscientes de la peninsularidad del territorio ibérico y en qué momento lo denominaron en su totalidad con el término Iberia. Al principio, el nombre de Iberia sólo denominaba a los territorios cercanos a la costa mediterránea ${ }^{2}$, y

\footnotetext{
${ }^{2}$ Así podría desprenderse de Her. 1, 163 donde se señala que "los habitantes de Focea, por cierto, fueron los primeros griegos que realizaron largos viajes por mar y son ellos quienes descubrieron el Adriatico, Tirrenia, Iberia y Tarteso" (Trad. C. Schrader 1992). También a partir del texto de Avieno se deduce que Iberia era sólo una pequeña zona entre el Guadiana y Río Tinto (ora marit. 244ss.) (Spranger 1960: 123).
} 
paulatinamente se fue ampliando a la totalidad de su extensión (Domínguez Monedero 1983: 203-211). Estrabón también deja claro que el término Iberia evolucionó en el tiempo: “(...) toda la región de más allá del Ródano y del istmo configurado por los golfos galáticos fue denominada Iberia por los autores antiguos, y en cambio los contemporáneos le señalan como límite el Pirene y dicen que Iberia e Hispania son sinónimos" (Str. 3, 4, 19. Trad. M.J. Meana y F. Piñero 1992). En cualquier caso, el carácter peninsular de la misma no se conocía todavía en el siglo V a.C., como se desprende de Hecateo de Mileto (Domínguez Monedero 1983: 211). El término Iberia tuvo un uso geográfico, y no étnico (Domínguez Monedero 1983: 214) y su nombre estuvo vinculado desde el origen a la riqueza de sus tierras en minas de oro, plata y estaño, así como a sus abundantes recursos agrícolas (Blanco Robles 2020: 320-322). Con la llegada de Roma el nombre de Iberia no se perdió, ya que siguió siendo el término utilizado por la comunidad grecoparlante.

Hispania fue el nombre con el que Roma identificó a la península Ibérica. Estrabón señala que “(...) los romanos por su parte, llamando indistintamente Iberia o Hispania a todo el territorio, dieron a una parte la denominación de Citerior y a la otra la de Ulterior" (Str. 3, 4, 19). No parece haber, por tanto, diferencias entre ambos términos ya desde época republicana.

El origen de la palabra Hispania ha sido muy discutido. Una de las hipótesis que ha tenido más éxito ha sido la de que su significado era "tierra de conejos", al hacerla derivar de saphan, conejo (Schulten 1934, Spranger 1960: 125). Esta opción tenía a su favor que las plagas de conejos eran muy abundantes en tierras hispanas (Catul. 3, 7, 18; Str. 3, 2, 6; 5, 2) y que, en algunas de las representaciones numismáticas con la figura de la provincia, aparece este animal (RIC Had. 305-306). Pero a finales del s. XX surgió otra hipótesis que descartó esta interpretación anterior y defiende que el término procedería del fenicio y significaría "costa de metales" o "isla donde se chapean o baten metales" (Cunchillos 2000). Es bien conocido que el interés por los metales fue la principal motivación por la que los fenicios llegaron a las costas hispanas (D.S. 5, 35, 4).

En las fuentes latinas el término Hispania aparece siempre aplicado a la península Ibérica en su totalidad, con la cota de los Pirineos como límite terrestre. Blázquez señala que esta concepción de unidad geográfica y de delimitación se remonta al menos a época de la guerra sertoriana, en el 72 a.C., cuando Pompeyo levantó un trofeo en la línea de división entre Hispania y la Galia (Blázquez Martínez 2005: 20). 


\section{Identidad y alteridad}

\subsection{Hispania, una creación romana}

La identidad y la alteridad durante época romana son dos temas de gran actualidad en la historiografía moderna (Cruz Andreotti y Mora Serrano 2004, Caballos Rufino y Lefebvre 2011, Mangas Manjarrés y Montero Herrero 2007). Los referentes identitarios de las sociedades y sus grupos se modelan según tres circunstancias: cómo se perciben a sí mismos, cómo son percibidos por "los otros" y cómo perciben "al otro". Son, por tanto, construcciones sociales percibidas de forma subjetiva ${ }^{3}$ (Beltrán Lloris 2011: 65, con bibliografía sobre este tema en n. 43-45). En este proceso los movimientos migratorios voluntarios o forzados (como los de las masas de esclavos introducidos en el mercado) tuvieron una gran importancia (de la Escosura Balbás 2019). Los nombres Hispania e Hispani fueron utilizados por Roma para denominar a la península Ibérica y a sus pobladores. Pero cabe preguntarse, ¿en qué grado fue aceptado por sus habitantes?

Antes de la conquista romana, los habitantes de la península no tenían conciencia de formar una unidad. Floro señala que Hispania "quedó sitiada por los romanos antes de que se conociera a sí misma y fue la única de todas las provincias que tuvo conciencia de sus propias fuerzas después de haber sido vencida" (Flor. 1, 33, 3-4. Trad. de G. Hinojo Andrés e I. Moreno Ferrero, 2008). Hispania fue, por tanto, una creación romana. Al contrario que otros territorios como Grecia, Galia, Britania o el norte de África, la península Ibérica conformaba un microcontinente heterogéneo en diversos planos culturales, lingüísticos y sociales (Beltrán Lloris 2011: 55-56). Puede sorprender que, con estas condiciones, Roma siempre la considerase como una unidad, a la que a menudo aplicó una política global. El ejemplo más destacado es la concesión del ius latii a todos los hispanos ("A toda Hispania concedió el emperador Vespasiano Augusto el derecho latino cuando estaba agitada por desórdenes políticos". Plin. N.H. 3, 30. Trad. de A. Fontán et al. 1998). Pero no es el único. La administración romana hizo uso de la totalidad del territorio hispano para gestionar algunas cuestiones como el cobro de las aduanas (AE 1924, 110=CIL XIV 4708) (P. Ozcáriz Gil 2013: 205-206). En época altoimperial el cargo de advocatus fisci tenía su rango de acción sobre Hispania en su conjunto 4 .

\footnotetext{
${ }^{3}$ Por tanto, no tiene sentido debatir aquí si el conjunto de los habitantes de Hispania tenía realmente unas características comunes que los definían como una unidad, sino si ellos mismos eran percibidos como una unidad desde fuera o si ellos se percibían a sí mismos como miembros de ella.

${ }^{4}$ Para aquellas cuestiones que no acarreaban excesivo trabajo en el terreno no es extraño encontrar cargos cuyo ámbito de acción supere el de una provincia. Por ejemplo, el procurador (funcionario administrativo) de las escuelas de gladiadores, L. Didius Marinus, ocupó el cargo simultáneamente para las provincias de Galia, Britania, Hispania, Germania y Retia durante el mandato de Septimio Severo (CIL III 6753= ILS 1396).
} 
Cuando Julio César y el emperador Adriano visitaron la península, convocaron concilios para toda ella, no uno por cada provincia (Caes. Bello Civ. 2, 21, 4-5 y HA, H. 12, 3-5. Alföldy 2014). De esta forma, las distintas divisiones administrativas provinciales convivieron con la concepción supraprovincial del territorio. Por ese motivo se designa indistintamente en singular (Hispania) o en plural (Hispaniae) (Beltrán Lloris 2011: 57, Spranger 1960: 134).

Roma nunca dejó de concebir Hispania como una unidad. Pero no administró toda la península como un distrito administrativo único, como una sola provincia, ya que no habría resultado viable. La provincia Hispania citerior o Tarraconense era la mayor de las tres provincias hispanas durante el alto Imperio. Era la más extensa de todo el Imperio romano, ocupando algo más de la mitad peninsular (P. Ozcáriz Gil 2013: 22). Sólo uno de sus siete conventos jurídicos, el cartaginense ${ }^{5}$, tenía aproximadamente la misma extensión que otras importantes provincias como Asia o la Bética. Para conseguir una administración eficaz en una provincia tan extensa, Roma tuvo que hacer adaptaciones administrativas "excepcionales", como destinar un legado jurídico permanente que ayudase al gobernador en la labor judicial, algo que no tenían otras provincias de tipo imperial (P. Ozcáriz Gil 2006-2007). En definitiva, no era concebible crear una única provincia que tuviese toda la extensión de la península Ibérica ${ }^{6}$.

El testimonio más antiguo de la utilización del término Hispania por parte de Roma se remite a la primera mitad del siglo II a.C. Se trata de la mención a los hispanos que hace Plauto (254-184 a.C.) cuando un personaje de la comedia Menaechmi está cansado de la búsqueda de su hermano gemelo perdido y señala: " - ¿Y cuándo vamos a acabar de buscarlo? Son ya seis años los que vamos tras ello. Hemos recorrido las tierras de los histrios, los hispanos, marselleses, ilirios, el mar Adriático todo, la Magna Grecia y todas las regiones de Italia que baña el mar. Si fuera una aguja lo que buscaras, creo que la hubieras encontrado ya hace tiempo, si es que estaba por alguna parte; estamos buscando entre los vivos a un muerto que, si viviera, ya hace mucho que hubiéramos dado con él” (P1., Men. 235. Trad. M. González-Haba, ed. Gredos 1996). Un poco después, Ennio (204-169 a.C.) pone en boca de un personaje las palabras "sepáis que hablo como hispano (Hispane), no como romano" (Ann. XXVI= $471=503 \mathrm{~V}$ ). Desconocemos quién las habría pronunciado, pero marca una clara división entre la perspectiva romana y la que el autor interpreta como hispana. Posteriormente, en un pasaje sobre el año 171 a.C. Tito Livio relata cómo hispanos de la Ulterior y la Citerior se unieron como un solo grupo para enviar una embajada a Roma. A todos ellos se les recibe como una unidad con

\footnotetext{
5 Los conventos jurídicos eran subdivisiones administrativas en las que estaban divididas las provincias hispanas.

${ }^{6}$ El mismo argumento de la extensión excesiva sirve para explicar por qué no se crearon provincias únicas con otras nationes como Galia o Germania.
} 
el nombre de Hispani (Liv. 43, 2). En el conocido "bronce de Ascoli" (CIL, $\left.I^{2}, 709\right)$, los jinetes reclutados entre diferentes pueblos del Valle del Ebro son identificados como equites Hispanos, y en los Fasti triumphales (CIL, I, pp. 168-181) se denominan de forma indistinta los triunfos sobre la Citerior o la Ulterior, así como los triunfos sobre Hispania sin mayor precisión, con la ambigüedad que ello genera.

Esta identificación por parte de Roma convirtió un mero espacio geográfico en un espacio con una identidad propia (sobre la imagen de Hispania: Cascón Dorado 2017, Gómez Espelosín 1995, Plácido Suárez 1995-6). Hasta finales de la República el nombre de Hispania aparecerá en las fuentes romanas generalmente unido a conceptos como la barbarie, algo que se mantendrá en algunas fuentes de los siglos I y II d.C. (Blanco Robles 2020: 322-324). Sin embargo, con la llegada de Augusto se va a producir un cambio en positivo en las connotaciones del término para la opinión pública de la capital. A finales del s. I a.C.-principios del I d.C., Estrabón señala que el tercer legado con el que contaba el gobernador de la Hispania citerior "(...) ejerce su vigilancia sobre el interior y gobierna los asuntos de los llamados ya togados, que es como decir que son pacíficos y que han pasado a un género de vida civilizado y al modo de ser itálico con su togada indumentaria. Son estos los celtíberos y los que viven cerca del Iber a ambas orillas hasta las zonas marítimas" (Str. 3, 4, 20). Las élites de estas comunidades que Estrabón identifica como "togados", que llevan un "género de vida civilizado y al modo de ser itálico" empiezan a formar parte del conjunto de la élite del Imperio: hombres de negocios, rétores, literatos y filósofos, así como el grupo de políticos más influyente de la capital. Este proceso irá unido a una modificación de la valoración del término Hispani. Lo que en un principio era barbarie y salvajismo, ahora se torna en virtud, como una digna y auténtica austeridad, sencillez y modo de vida rústico, conceptos muy integrados en el código de valores romano, el mos maiorum (Blanco Robles 2020: 330, Beltrán Lloris 2011: 76-77). Es decir, que los valores que habían definido desde sus orígenes a las familias patricias romanas, y que a finales de la República se habían perdido por la crisis moral, se hacen presentes en la noble rusticidad de los pueblos hispanos. Este proceso debió ser muy parecido al que ya antes se había producido con el fin de integrar a los pueblos latinos en la órbita romana (Beltrán Lloris 2011: 75). Esta evolución permitió que las élites hispanas pudiesen ir acomodándose en la nueva identidad adaptada por Roma (Blanco Robles 2020: 331-332).

Esta evolución de la percepción romana de estos pueblos que se englobaban bajo el término Hispania se puede apreciar de forma visual en las imágenes personificadas de la provincia. Desde el s. I d.C. se empiezan a elaborar imágenes con personificaciones femeninas de Hispania y de otros territorios. No aparecen las tres provincias hispanas individuales, sino una 
sola que representa a Hispania en su conjunto (Beltrán Lloris 2011: 60-61, con bibliografía en la n. 21 y ss.). La importancia que el emperador Augusto otorgó a estas alegorías como parte de su programa político imperial se percibe en que las estatuas de Hispania que mandó erigir en el foro eran de oro puro (Alföldy 1989). Más adelante, es conocida la representación de Hispania situada en templo de Adriano (Méthy 1992). Las características y detalles aplicados a estas figuras femeninas eran un trasunto de la personalidad de la natio representada. Los detalles que se incluyen en ellas hacen referencia a tal personalidad, describiéndola, pero a la vez consolidándola y reforzándola. Existen representaciones de este tipo de muchas provincias. La mayoría son provincias individuales, pero también, como ocurre en el caso hispano, nationes que abarcaban más de una, como Galia, Germania, Moesia o Mauretania (Méthy 1992). La evolución se puede analizar mejor en las imágenes de este tipo representadas en las monedas. Mientras que a finales de la República y en la época augustea, Hispania aparece con aspecto bárbaro o vencido, en época altoimperial evolucionará hacia la figura de una mujer civilizada, portadora de espigas de trigo o ramas de olivo (Beltrán Lloris 2011: 63-64).

Pero esta evolución de la percepción no se completó hasta el final de época altoimperial. Desde el punto de vista romano, tener origen provincial era un obstáculo a la hora de progresar en la política imperial al comienzo del Imperio. También lo fue-sin duda- para los hispanos. Pero a pesar de ello un hispano, Lucio Cornelio Balbo, fue el primer no itálico en ser nombrado cónsul (40 a.C.). Su sobrino, homónimo, fue el primer no itálico en conseguir el triunfo (19 a.C.). Dos miembros de familias hispanas, Trajano y Adriano, fueron los primeros emperadores de familia no itálica. A menudo se hace hincapié en que éstos no hicieron gala de su hispanidad. En el panegírico de Trajano, se menciona su origen hispano de forma muy ambigua (Plin., Pan. 14, 5). Sordi muestra que a los primeros emperadores de origen provincial no les agradaba que les fuese recordado su origen y buscaban conscientemente antepasados romanos o, al menos, itálicos (Sordi 2002: 317-319). Pero, aunque este origen hispano no les beneficiase especialmente, es obvio que tampoco fue un impedimento demasiado significativo, puesto que, siendo conocido por todos, accedieron al mayor de los honores. Esta circunstancia cambia de forma significativa más de dos siglos después en el panegírico de Teodosio. Ahí Pacato, autor del texto, menciona el origen del emperador con las siguientes palabras: "Pues, en primer lugar, tienes por madre a Hispania, la tierra más afortunada entre todas las tierras, que el supremo hacedor de las cosas se ha complacido en embellecer y enriquecer mucho más interesadamente que al resto de los pueblos; al no estar expuesta a los calores del Sur ni sujeta a los fríos del Norte, se ve favorecida por una temperatura intermedia entre ambos extremos (...). Ella da a luz a los soldados más aguerridos, ella a los generales con más experiencia, ella a 
los oradores más elocuentes y emperadores. Ella proporcionó al Imperio al insigne Trajano y después a Adriano; a ella el Imperio le debe tu persona (...)" (Trad. de José Miguel Baños en: Mangas Manjarrés y Myro 2003: 163-164). La evolución del concepto Hispania es evidente.

\subsection{Hispania como referencia del origo e identidad propia.}

El término Hispania fue utilizado por los propios Hispani para referirse a sí mismos probablemente desde la llegada de Roma a la península. El primer ejemplo del que tenemos noticia podría ser el de los mercenarios hispanos que ayudaron a Roma en el 212 a.C. y fueron asentados en la ciudad de Morgantina en Sicilia (Liv. 26, 21, 9-17). Emitieron una moneda con la leyenda Hispanorum, a pesar de que lo hicieron en un contexto griego. Según Caltabiano, el momento de la acuñación debería datarse a finales del s. III o comienzos del II a.C. (Caltabiano 1985, Beltrán Lloris 2011: 67-69). Si esta interpretación es correcta, indicaría que estos mercenarios habían asimilado ya su condición de "hispanos", en un momento cercano al final de la segunda guerra púnica y la división en provincias de Hispania (197 a.C.).

Los nacidos en la península Ibérica no tenían una forma "oficial" de denominar su origen, más allá de su ciudadanía local. Ni siquiera los funcionarios más elevados de la administración hispana denominan los territorios gobernados por ellos de la misma forma (P. Ozcáriz Gil 2013: 107-108; 156-158). Los hispanos de época altoimperial, para identificarse, podían hacer referencia a varios niveles geográficos: el nivel local (su ciudad), intermedio (su comunidad no urbana, la regio o el conventus), provincial (la Bética, Lusitania o la Hispania citerior/Tarraconense) o el de la natio(Hispania), según les conviniese por su opción personal. Estos múltiples niveles no son incompatibles entre sí. Una mujer llamada Calpurnia Ilias falleció en Roma en el s. II. d.C. Recibió sepultura en la capital del Imperio y su marido, L. Lusius Menecrates le erigió una inscripción en la que se le presenta como Eborensis ex Lusitania (CIL VI 14324). Es decir, de la ciudad de Évora, en la provincia Lusitania. Otros casos parecidos son los de C. Cornelius Iunianus, ex Hispania citeriore Saetabitanus (de la provincia Hispania citerior, de Saetabis. CIL VI 16247) o el de Lucifera, ex Hispania Ev(andriana) (de Hispania, de Evandria. CIL VI 21569), o el de Phoebus qui et Tormogus, Hispanus natus Segisamone (hispano, nacido en Sasamón. CIL VI 24162). L. Hostilius Saturninus falleció en Burdigala (Burdeos) y un esclavo suyo dejó constancia de que su amo fue Hispanus Cournoniensis, es decir, hispano procedente de la ciudad vascona de Curnonium, probablemente la actual Los Arcos (Navarra) (CIL XIII 621). En época más tardía esta estructura se mantiene, por ejemplo, en los tres niveles que se utilizan al dar a conocer el origen del emperador Teodosio que ofrece 
Hidacio (s. V. d.C.) en su crónica, (Chron. 2): Theodosius natione Hispanus, de provincia Gallaecia, civitate Cauca (...). Es decir, informa de su natio (hispana), provincia (Gallaecia) y municipio (Cauca).

Estos diferentes niveles también fueron utilizados por Roma para denominar las unidades militares auxiliares reclutadas en territorio hispano (Roldán 1974: 51ss.; 265ss.; 361ss.; 528-532, Roux 1982: 93-98; 145-146). Si la unidad procedía de una región, comunidad, provincia o grupo étnico, recibían el nombre propio del sitio. Por poner algún ejemplo, en Volubilis (provincia de Mauretania Tingitana, actual Marruecos), Nammius Maternus señala en una inscripción que fue praef(ectus) cohor(tis) Astur(um) et Callaecor(um), es decir, prefecto de la cohorte de astures y galaicos (AE 1916, 91). O el soldado veterano Q(uintus) Allidius Celer, señala que formó parte durante 26 años de la cohors I Lusitanorum (AE 1957, 0189). Falleció a los 50 años en la antigua ciudad de Tomis, en la provincia Moesia inferior, actual Rumanía. En el caso de que la leva se realizase con individuos de orígenes más dispersos, se optaba por el genérico Hispani. Conocemos numerosos ejemplos de cohortes y alas Hispanorum. T. Statius Praetuttianus fue tribunus cohortis II Hispanorum equitata civium Romanorum, en este caso una segunda cohorte hispana, a caballo, de ciudadanos romanos. En algún caso se mezclan las denominaciones regionales y la de Hispania, como ocurre en la inscripción del soldado Reburrus Coroturetis muerto en la provincia Germania inferior. Durante 24 años sirvió en la cohors I Lucensium Hispanorum pia fidelis. Es decir, en la primera cohorte de lucenses (procedentes de Lucus Augusti o del convento lucense) hispanos. Un caso parecido es el de la segunda cohorte de vascones, atestiguada en lugares como Germania, Britania o el norte de África. En ocasiones es mencionada como Cohors II Vasconum civium Romanorum (CIL XII 3183), y en otras se le añade el epíteto de Hispana o Hispanorum tras el numeral, probablemente como forma de aclarar su origen (AE 1950, 0067; CIL XII 3183).

Como hemos visto antes, tener origen provincial en Roma no ayudaba especialmente a ascender en la escala social, aunque en el caso hispano tampoco fue un impedimento demasiado difícil de superar. Roma fue el principal destino de los emigrantes hispanos (de la Escosura Balbás 2019: 333-334) y allí unieron sus lazos de forma estrecha (Alföldy 2001). Los políticos hispanos configuraban un grupo en Roma con intereses comunes desde época JulioClaudia, pero fue en época Trajanea cuando alcanzaron su mayor influencia dentro del ordo senatorial (sobre los senadores hispanos, cf. Caballos Rufino 1990). Sin embargo, no parece que formasen un "partido político" como se ha llegado a proponer (des Boscs-Plateaux 2005). Según palabras de Alföldy, "la aristocracia senatorial de Hispania no sólo estaba presente en la Roma imperial de forma habitual, sino que se esforzaba por ser especialmente llamativa en 
ella. No querían aparecer en la capital del imperio como un grupo de extranjeros o inadaptados, sino como parte de la aristocracia de Roma, como un grupo distinguido de buenos romanos" (Alföldy 2001: 88). De esta aristocracia senatorial formaron parte muchos de los literatos de época Julio-Claudia y Flavia, los cuales tampoco se prodigan en mencionar de forma abierta su origen hispano (Blanco Robles 2020). Tampoco otros como el calagurritano Quintiliano mencionan de forma destacada su condición de provinciales. Pero la excepción a esta tendencia, el poeta bilbilitano Marcial, es un testimonio de extraordinaria importancia. Transmite la plena aceptación por parte de algunos hispanos de su condición de romano y de hispano y en algún caso adelanta los textos de alabanza idealizada de Hispania que se harán más populares en cronologías más avanzadas ("Varón que no debe ser silenciado entre los pueblos celtíberos, loor de nuestra Hispania [nostraeque laus Hispaniae]". Ep. $1,49)$ Su proceso de integración en la capital se realizó gracias a ese mismo grupo de hispanos como la familia de los Séneca (Beltrán Lloris 2011: 74). Pero al contrario de lo que sucede en los textos de ese círculo, en los textos de Marcial sí se percibe el orgullo de haber nacido en tierra hispana, y lo hace como contraste frente a la decadencia de la vida urbana en la capital (Ep. 4, 55). En su caso existe un claro sentimiento de afecto a su tierra de origen. En sus epigramas se deja constancia de que los hispanos, incluido él mismo, tenían unas características (quizás podríamos llamarlas tópicos) que los identificaban:

Si presumes de que eres paisano de los bronces Corintios ${ }^{7}$, Carmenión, sin que nadie lo niegue, ¿por qué me llamas hermano a mí, que he nacido de iberos y celtas y soy vecino del Tajo?

¿O es que damos la impresión de parecernos en la cara?

Tú deambulas radiante, con el cabello ondulado, yo, incorregible con mis pelos hispanos; tú, terso por el depilatorio de cada día, yo, con mis piernas y mejillas peludas; tu boca es premiosa y tu expresión débil, más alto que yo hablará fulanita; no es tan distinta la paloma al águila ni la asustadiza gacela al impertérrito león.

Por tanto, deja de llamarme hermano no vaya a ser, Carmenión, que te llame hermana.

(Ep. 10, 65. Trad. J. Fernández Valverde y A. Ramírez de Verger. Ed. Gredos 2001)

Se trata de un claro ejercicio de refuerzo de la identidad propia frente al diferente. Frente al "afeminado" y delicado griego, Marcial se presenta como

\footnotetext{
${ }^{7}$ El texto compara las personalidades de un griego y un hispano.
} 
un hispano impregnado de la "virtuosa rusticidad" antes mencionada. Quizás de cara a cierta opinión pública no sería tan virtuosa y podría interpretarse como personalidad provinciana. Esto explica por qué Trajano, Adriano u otros políticos no hacen gala de su carácter hispano, puesto que están haciendo carrera política frente a itálicos y romanos. Pero desde el punto de vista de los hispanos, Marcial demuestra que ya desde época Julio-Claudia y Flavia existe un perfil propio, asumido, de "hispano" y un vínculo emocional entre los Hispani que viven fuera de su provincia hacia su tierra de origen. En otros versos, vuelve a reconocer lo rústico de su carácter, pero a la vez el orgullo de ser de ese modo: "a mí, nacido de celtas e iberos, no me avergüence poner en versos agradables los nombres rudos de mi tierra" (Ep. 4, 55. Trad. J. Fernández Valverde y A. Ramírez de Verger. Ed. Gredos 2001). A partir de Marcial resulta imposible defender que el término Hispania tenía exclusivamente un significado geográfico y no identitario ${ }^{8}$. El propio Marcial expresa la existencia de estos dos conceptos (origen geográfico y características culturales propias que identifican un territorio) en la introducción a su libro XII cuando le pide a su amigo Prisco que lea el manuscrito antes de mandarlo a Roma para que se publique allí y "que emitas un veredicto sobre mis fruslerías dejando a un lado la amabilidad, no vaya a ser que envíe a Roma - si tu fallo es favorable- un libro, no hecho en Hispania, sino hispano (non Hispaniensem librum mittamus, sed Hispanum)" (Ep. 12, pr. Trad. J. Fernández Valverde y A. Ramírez de Verger. Ed. Gredos 2001) ${ }^{9}$.

\section{La fórmula natione Hispanus}

\subsection{El término natio}

Existen pocos términos más controvertidos en la sociedad actual que el de "nación". No entraré aquí a analizar en profundidad su significado moderno, más allá de mencionar que, según la RAE, las tres acepciones principales del término son: 1. El conjunto de los habitantes de un país regido por el mismo Gobierno. 2. Territorio de una nación. 3. Conjunto de personas de un mismo origen y que generalmente hablan un mismo idioma y tienen una tradición común. A lo largo de la Historia el término natio ha variado, sobre todo en los últimos siglos, incorporando elementos tanto políticos y administrativos

\footnotetext{
${ }^{8}$ Esta identidad no debe interpretarse como una identificación "nacional" en el sentido actual de la palabra, sino como un sentimiento común de que se comparten unas características generales comunes, poco precisas y sin trascendencia política.

${ }^{9}$ El autor está aquí utilizando el rasgo de personalidad hispana de la rudeza utilizado también en Ep. 10, 65. Entiende que se trata de una virtud cuando se trata de un rasgo de su personalidad, como en Ep. 4, 55, pero no en un trabajo intelectual como una obra literaria.
} 
como otros relacionados con la autopercepción, el reconocimiento externo, la afectividad o el sentimiento.

Para entender qué significaba el término en época romana, en primer lugar debemos acudir a las fuentes clásicas y a los diccionarios de referencia. Según Pomponio Festo, por natio se entiende la "raza de hombres que no vino de otra parte, sino que nació en el suelo que habita. También en los rebaños, el buen producto de una camada se llama bona natio" (Fest. 166). Según Cicerón, la natio es un elemento que une a las comunidades humanas junto con la gens (el tener una descendencia común) y el idioma y resulta una forma muy sólida de asociación (Cic. Off. 1, 53). Según el Oxford Latin Dictionary (ed. 1968: 1158), la palabra natio tiene las siguientes acepciones: 1. El nacimiento de un niño. Una diosa del nacimiento adorada en Ardea. 2. Un pueblo, raza, nación. Ad nationes, el nombre de un pórtico de Roma. 3. Grupo de personas de una clase, tipo. 4. Raza como característica de las personas, nacionalidad. 5. El lugar de origen de productos naturales ${ }^{10}$.

La primera conclusión que podemos sacar de esta variedad de acepciones es que el término no resulta sencillo de definir. Deriva de la palabra natus, el participio de perfecto pasivo del verbo nascor (nacer), la cual está a su vez conectada con numerosos términos relacionados con el nacimiento y el parentesco. Su uso en contextos relacionados con el nacimiento de un niño o de un animal es generalmente de época republicana (Var. $R$. 2, 6, 4; CIL XIV 2863).

En un segundo momento, desde finales del siglo III-principios del II a.C., se empezó a utilizar para definir a un conjunto de personas con un origen común (Adams 2007; 19, Kočovska-Stevović 2016: 5-6). Estos grupos siempre eran externos a Roma. Los romanos nunca se autoidentificaron como natio. Existía el populus Romanus, pero no una natio Romanorum (Zernatto 1944: 352). El uso de esta acepción lo encontramos en primer lugar en Plauto. Este autor utiliza este sentido de la palabra con matices diferentes. En primer lugar, como lugar común en sentido metafórico. Se puede referir a un grupo humano que comparte valores (o la falta de ellos), intereses o actividades (Kočovska-Stevović 2016: 7). Por ejemplo, Plauto se refiere a un grupo de pescadores de poca monta con el término natio en un texto que ha sido traducido de la siguiente forma: "Salud, rateros marítimos, rebuscadores de conchas y pescadores de caña, raza de hambrientos (famelica hominum natio), ¿qué tal andáis?, ¿qué tal se va muriendo?" (P1. Rud. 310ss. Trad. M. González-Haba. Ed. Gredos 2002). Muy a menudo el término se utiliza de modo peyorativo, con gente de los bajos fondos, o de pueblos bárbaros y percibidos como inferiores (Kočovska-Stevović 2016,

10 La utilización del término como lugar de origen de productos naturales se la debemos principalmente a Plinio el Viejo, quien hace uso de esta acepción con bastante asiduidad (Plin. Nat. 21.83, 24.34, 29.33)

Araucaria. Revista Iberoamericana de Filosofia, Politica, Humanidades y Relaciones Internacionales, año $23, \mathrm{n}^{\circ} 47$. Segundo cuatrimestre de 2021. Pp. 21-45. ISSN 1575-6823 e-ISSN 2340-2199 https://dx.doi.org/10.12795/araucaria.2021.i47.02 
Zernatto 1944: 352, Walbank 1972: 156). En otro caso, Plauto utiliza el mismo término refiriéndose al grupo de personas nacidas en un lugar, en este caso una ciudad: "Caray, según yo creo, como no te vuelvas a casa, cuando te encuentres sin nada, entonces vas a tener que gemir mientras que buscas al gemelo. Porque esta gente de aquí (haec hominum natio), los de Epidamno, son muy dados a la disipación y muy bebedores, y luego que viven aquí muchísimos picaros y estafadores" (P1. Men. 256ss. Trad. Trad. M. González-Haba. Ed. Gredos 1996). En un tercer caso utiliza el mismo significado de "grupo de personas nacidas en un mismo lugar", pero a la vez asumiendo que ese dato conlleva la identificación con unas características físicas, culturales o sociales comunes: "Gorgojo: Te diré; es que hace tres días que hemos vuelto a Caria de la India; se quiere encargar allí una estatua maciza de oro filípico de más de dos metros de altura, para conmemorar sus hazañas. Licón: Y eso ¿por qué? Gorgojo: Yo te lo diré: porque a los persas, los paflagonios, los sínopes, los árabes, los carios, creíanos, sirios, Rodia y Licia, Tragolandia y Bebilandia, la Centauromaquia y la armada de las monomamias, toda la costa líbica y toda la Conterebromia, o sea, la mitad de todos los pueblos del orbe (dimidiam partem nationum usque omnium), los ha sometido él solo en menos de veinte días" (P1. Cur. 439ss. Trad. M. González-Haba, ed. Gredos 1996). En un último ejemplo, el término denomina a un grupo de gente de amplitud intermedia, el del conjunto de los nacidos en Sicilia: "Hegión: Pero, ¿por qué juras por esas ciudades extranjeras? Ergástilo: Pues porque tienen unos nombres igual de ásperos, como decías tú de tus comidas. Hegión: ¡Ay de... Ergástilo: ... ti! por no creerme lo que te digo con toda verdad. Pero Estalagmo, ¿qué nacionalidad (tunc nationis) tenía cuando se fue de aquí? Hegión: Siciliana. Ergástilo: Pues ahora no es siciliano, sino del país de los boyos, porque duerme con un virote de esos que llaman boia; yo creo que se la han dado por esposa, a ver si tiene hijos" (P1. Capt. 887. Trad. M. González-Haba, ed. Gredos 1992). En este caso el personaje Ergástilo pregunta a qué natio pertenece el esclavo de Hegión que había raptado a su hijo. La finalidad de la pregunta no sería conocer el lugar geográfico de su nacimiento, si ese dato no aportase información de cara a su identificación. Hegión le responde con una referencia de nacimiento -siciliano-, que el interlocutor identificaría inmediatamente con unos rasgos culturales y físicos bien definidos. A continuación, Ergástilo le responde haciendo una broma con otra referencia al pueblo de los boyos (un pueblo galo) haciendo un juego de palabras con el nombre de "boia", un tipo de virote que se llevaba al cuello y que le identificaba como esclavo.

En el pasaje de De Officiis de Cicerón mencionado antes, incluye la natio -junto a la gens y la lingua- como elemento de cohesión social. Por encima se encontraba el conjunto de la humanidad en general y por debajo la ciudad. El texto es el siguiente: "La comunidad y vinculación de los hombres se 
mantendrá si, cuanto más unido está alguien a uno, tanto mayor benevolencia se manifiesta. Pero parece que, en cuanto a cuáles son los fundamentos naturales de la asociación y comunidad humanas, hay que reconsiderarlo con más profundidad. Lo primero es lo que se observa en la vida en comunidad de todo el género humano. El nexo de esta es la razón y el lenguaje (...). Y esta comunidad está totalmente a disposición de los hombres entre sí, de todos entre todos (...). Por otra parte, en la comunidad humana hay muchos grados. En efecto, desentendámonos de aquella ilimitada; algo más cercana es la de la estirpe (gentis), del pueblo (nationis) o lengua -la que más reúne a los hombres-. Más dentro queda el ser de la misma ciudad" (Cic. Off. 1, 50ss. Trad. de I.J. García Pinilla, ed. Gredos 2014). Sobre este texto, Walbank opina que gens y natio son las palabras perfectas para definir a una comunidad tribal (Walbank 1972). En base principalmente a la obra ciceroniana, la Dra. Kočovska-Stevović establece tres usos principales del término natio: 1. El aplicado a una persona que pertenece a una tribu específica. 2.- El aplicado a los habitantes de una región o país específico. 3. El aplicado a los habitantes de una ciudad específica (Kočovska-Stevović 2016: 10).

En definitiva, las acepciones son muchas, pero la que aquí nos ocupa, de cara a la aplicación a los hispanos, es la que se utiliza para identificar a grupos humanos que tienen un mismo origen geográfico, municipal, provincial, tribal, cultural, de raza o de otro tipo, que los define frente al resto, independientemente de que tengan una organización administrativa estructurada o no.

\subsection{Natione Hispanus/a}

\subsubsection{En la literatura}

La palabra natio en referencia a Hispania aparece en varias ocasiones en las fuentes literarias latinas. El término se utiliza según las acepciones ya vistas, aunque cada autor las aplica según su preferencia.

Cuando se utilizan las palabras natione Hispanus/a se hace referencia a toda la península Ibérica. Cicerón, por ejemplo, lo utiliza en contextos en los que quiere destacar el carácter bárbaro y belicoso de sus tierras: hablando sobre el gobierno en Asia de su hermano Quinto, afirma: “(...) pero si el azar te hubiera puesto sobre los africanos, los Hispani o los galos, naciones salvajes y bárbaras (immanibus ac barbaris nationibus)" (Q. fr. 1, 1, 27, 5). Plinio utiliza a menudo el término natio para referirse al origen de productos naturales. En el caso de Hispania, la menciona entre las nationes olei es decir, los territorios de donde es originario el aceite de oliva (Plin Nat 1, 15, 7). Vitrubio, haciendo referencia a una técnica constructiva antigua, señala que "hasta hoy en día se siguen construyendo edificios con estos materiales por naciones extranjeras 
(nationibus exteris), como en Galia, Hispania, Lusitania, Aquitania (...)" (Vitr. 2, 1, 4, 3). Resulta interesante que, tras mencionar como nationes a Galia e Hispania, añada Lusitania y Aquitania aparentemente al mismo nivel, puesto que son dos provincias que forman parte de los territorios anteriores. Suetonio utiliza la expresión natione Hispanus para señalar el origen del gramático $C$. Iulius Hyginus, liberto del emperador Augusto, de quien algunos decían que había nacido en Alejandría (Alexandrinum putant. Suet. Gram. 20, 1, 1). En estos casos, Hispania se encuentra al mismo nivel que otras nationes como Galia, África, Germania, etc.

El término natio también se utiliza para territorios intermedios o grupos de gentes de la península. Frontón relata que Cornelio Nepote dejó constancia de que "En la guerra antes mencionada (la de Numancia) acudían hombres procedentes de todas las naciones de Hispania (viri e nationibus adducti Hispaniae)" (Fro Ver. 2, 1, 18, 13). En este caso se utiliza la natio como forma de identificar a algunos de los pueblos que formaban parte de Hispania. También encontramos el concepto de natio aplicado a otros pueblos hispanos como los celtíberos (Veg. Ep. 2, 2; Catul. 9, 6).

En otros casos, el término se utiliza como referencia a la ciudad de origen de un personaje. Tácito no usa el término natio para referirse a Hispania. Pero en sus Anales, hablando del conocido episodio en el que un termestino asesinó al legado de Roma en la provincia, aplica el término natio de la siguiente manera: "En el mismo consulado, un crimen atroz fue cometido en la Hispania Citerior (in citeriore Hispania) por un campesino del pueblo termestino (nationis Termestinae)" (Tac. Ann 4, 45. Trad. de J.L. Moralejo, ed. Gredos 1979) ${ }^{11}$.

\subsubsection{En la epigrafía}

En todos estos casos mencionados en el punto anterior, la palabra natio se ha utilizado desde una perspectiva externa a Hispania, hablando de este territorio en tercera persona. Sin embargo, en la epigrafía, el término natio se utiliza por los propios hispanos para referirse a sí mismos. Contamos con los siguientes ejemplos ${ }^{12}$.

1. Inscripción hallada en Roma. Se trata de una inscripción sepulcral de mármol fechada entre los años 117 y 161 d.C. ${ }^{13}$.

\footnotetext{
${ }^{11}$ Se trata de una referencia a la ciudad celtíbera de Termes (Tiermes, Soria)

${ }^{12}$ En este caso ofrecemos el listado completo de inscripciones con este término, puesto que no se ha recogido hasta ahora. Hemos decidido no incluir la inscripción CIL XIII 259 (Canpan[us nat(ione)] / H(ispanus) Iul(ia) Nou(a) [ Karth(agine)]) ya que la reconstrucción del término nat(ione) no es del todo segura.

${ }^{13}$ CIL VI 13820, p. $3514=$ Ricci 1992, $111=$ EDR100506
} 
D(is) M(anibus) s(acrum) / Caeciliae Graeculae / natione Hispana / vixit ann(is) XL. / P(ublius) Aelius Menophilus / coni(u)gi carissimae / fecit.

Cecilia Graecula señala en su inscripción funeraria que era de la natio hispana, sin aportar más detalles. Se trata de un nombre bastante particular, cuyo origen ya haría referencia a su procedencia, sin necesidad de precisarlo ${ }^{14}$. Vivió cuarenta años, y se encargó de su epitafio su marido, Publio Aelio Menófilo.

2. Inscripción procedente de Roma. El soporte es un cipo funerario fechado en el s. I d.C. ${ }^{15}$

D(is) M(anibus) / Cn(aeo) Turranio / Eutycheti / Primulus tatae / suo benemerent(i) fecit; / $\bar{n}$ (atione) Hispanus is qui fecit

Primulus es nombre del encargado de erigir la inscripción a Cn. Turranius Eutyches, a quien denomina tata. Ésta es una forma familiar o infantil utilizada para la palabra "padre" o "abuelo".

3. Inscripción honorífica procedente de Roma dedicada al famoso auriga Diocles, entre los años 146 y 150 d.C. ${ }^{16}$.

[C(aius) Appu]leius Diocles agitator factionis russatae / [nati]one Hispanus Lusitanus annorum XXXXII mens(ium) VII d(ierum) XXIII (y 13 líneas más)

Diocles fue uno de los aurigas más famosos del Imperio romano (de la Escosura Balbás 2012). Esta inscripción, procedente de Roma y perdida en la actualidad, era de grandes dimensiones. Se ha conservado la lectura bastante completa. Se indica que tenía 42 años, 7 meses y 23 días cuando se retiró. En ella se hace un recorrido por la trayectoria de los equipos por los que pasó, el número de victorias (1462) y que sus ganancias ascendieron a 35.863.120 sestercios (García y Bellido 1955: 252-253). También se precisan datos como el número de carreras ganadas al sprint, carreras ganadas tomando la delantera desde la salida, contra cada uno de los equipos rivales, etc. Se le compara con los otros aurigas famosos con el fin de ensalzarlo. La inscripción apareció en los alrededores del Vaticano, puesto que habría sido instalada en las cercanías del circo de Calígula y Nerón.

Al tratarse de un deportista de élite, su origen adquiere una relevancia especial. La inscripción pudo ser encargada por algún seguidor o grupo

${ }^{14}$ El nombre Graecula aparece en tres ocasiones en Lusitania (AE 1976, 274b; AE 2003, 882; IRCP 650), en la Bética (AE 1998, 747; HEp 14, 2005, 324;) y en la Tarraconense (CIL II 4418) pero también hay un caso en Numidia (CIL VIII, 18821), y otros dos en Roma (CIL VI 8552 y 26439).

${ }^{15}$ CIL VI 5337=Ricci, 1992, 120=EDR100501

${ }^{16}$ CIL VI 10048= ILS, 5287=AE, 2008, 176=EDR102150=AE, 2006, 1866 
de seguidores que quisieron ensalzar su figura en la sede de muchas de sus victorias (García y Bellido 1955: 253-254). Y su condición de hispanus aparece destacada. A continuación de Hispanus se añade Lusitanus precisando, bien la provincia administrativa en la que nació, bien su pertenencia al pueblo lusitano (Lefebvre 2011: 167). La siguiente inscripción también hace referencia al mismo personaje.

4. Inscripción honorífica a Diocles procedente de Praeneste (actual Palestrina, Italia $)^{17}$

C(aio) Appuleio Diocli / agitatori primo fact(ionis) / russat(ae) natione Hispano / Fortunae Primigeniae / d(onum) d(ederunt) / C(aius) Appuleius Nymphidianus / ẹt Nymphidia, filii

Segunda inscripción realizada a favor del auriga Cayo Apuleyo Diocles, ésta en su ciudad de residencia. En este caso se trata prácticamente de una autorrepresentación, ya que la inscripción está dedicada por sus dos hijos. Se encuentra dirigida a la divinidad de la Fortuna Primigenia, con el fin de que su padre tuviese el apoyo de la diosa. Los datos que se aportan de su padre son: su profesión (agitator), su pertenencia al equipo rojo, y ser natione Hispano, sin querer precisar más. En el caso de Diocles, que ambas inscripciones utilicen la misma fórmula, es un signo claro de que desea ser identificado de esa forma.

5. Inscripción procedente de Settepolesini (Italia), datada en la primera mitad del siglo II d.C. ${ }^{18}$

$D$ (is) M(anibus) / T(ito) Iulio Urb/ano na(tione) Hisp/ano milit(avit) in / leg(ione) VII gemi/na felice vi/xit an(nos) LX / mil(itavit) an(nos) XXVI / her(es) Iulia Pu/sinca / pa(trono?) b(ene) m(erenti)

Inscripción funeraria de T. Iulius Urbanus. Fue un antiguo legionario de la legio VII gemina felix. Esta legión tuvo su sede, en el momento de la datación de la inscripción, en Legio (León), con lo que debió ir a Italia tras ser licenciado. La inscripción indica que murió a los 60 años y militó en la legión durante 26. Fue dedicada a su patrono por Iulia Pusinca. Se identifica a Urbano como natione Hispanus, sin más detalle.

6. Inscripción procedente de Corduba, fechada en la primera mitad del siglo $\mathrm{II}^{19}$.

${ }^{17}$ CIL XIV 2884=264=EDR119535.

${ }^{18}$ AE 1978, 342= (Mansuelli 1967: 154-155) $=$ HD004826

${ }^{19}$ AE 1962, 51=CIL II ${ }^{2}$ 07, 364=EAOR 32, p. 110=HD016519

Araucaria. Revista Iberoamericana de Filosofí, Política, Humanidades y Relaciones Internacionales, año $23, \mathrm{n}^{\circ} 47$. Segundo cuatrimestre de 2021. Pp. 21-45. ISSN 1575-6823 e-ISSN 2340-2199 https://dx.doi.org/10.12795/araucaria.2021.i47.02 
------] / [--]R[---] / nation[e ---] / tr(aex) / Sagitta [---]M[---] / natione Hispanus / h(ic) s(iti) s(unt) s(it) v(obis) t(erra) l(evis) / conservi de suo bene merentib(us).

Se trata de una inscripción funeraria dedicada a dos gladiadores por sus conservi, es decir, sus compañeros de condición servil de familia gladiatoria. El nombre del primero se ha perdido y del segundo se conserva la palabra Sagitta (flecha), que podría hacer referencia al nombre o a un epíteto que acompañaba a su nombre (Gómez-Pantoja 2009). Este segundo gladiador se identifica como natione Hispanus. Resultaría extraño que utilizase esta identificación siendo realizada en la propia Hispania donde se daría por hecho que la mayoría lo era. Sin embargo, se trata de una lápida sepulcral de dos gladiadores. La natio, que define sus características como luchador, se convierte en un dato muy relevante (Ceballos Hornero 2003: 326-327).

7. Inscripción funeraria procedente de Viminacium (provincia Moesia superior), actual Požarevac (Serbia), fechada en el siglo II d.C. ${ }^{20}$

------] / L(ucius) Pla[---]/rius L(uci) [f(ilius) ---]/us Ga[ditan(us)?] / pago R[---] / [--- natio]/ne Hisp[anus] / vixit ann(os) [---] / mil(itavit) an[n(os) ---

La inscripción pertenece al epitafio de L. Pla [---]rius L.[f. ---]us. Se trata de un soldado, ya que se incluye la fórmula militavit annos sin llegar a conservarse el número de años correspondiente. En este caso el origen del personaje se pudo expresar a tres niveles diferentes. En primer lugar las letras $G A[---]$ han sido reconstruidas como Ga[ditan(us)?] (HD036079). A continuación la referencia a un pago $^{21} R[---]$, y finalmente a la natio Hispana.

8. Inscripción funeraria procedente de Carnuntum (Pannonia superior, actual Austria), fechada entre los años 171-200 d.C. ${ }^{22}$

T(itus) Aur(elius) Silvanus vet(eranus) ex magistr(o) / navalior(um) leg(ionis) XIIII g(eminae) nation(e) / Hispan(us) Tarraconensis / ann(orum) LXXXI vivus sibi et / Aeliae Iustinae coniug(i) / obsequentissimae et / Aureli(i) $s$ Maximinae an(norum) / VII Marco ann(orum) V et Floro / ann(orum) V fili(i) s pientissimis / [------] / [------

Inscripción funeraria del veterano Titus Aurelius Silvanus. Debió servir en los navalia de la legio XIIII gemina. En este caso, al igual que en el caso del auriga Diocles, podemos afirmar que él mismo fue quien se autodenominó

\footnotetext{
20 IMS 2, 149=HD036079.

${ }^{21}$ Un pagus es un distrito de un municipio, o una aldea dentro del territorio perteneciente a un municipio.

22 AE 2010, 1261=AE 2013, 1244=HD067801.
}

Araucaria. Revista Iberoamericana de Filosofia, Política, Humanidades y Relaciones Internacionales, año $23, \mathrm{n}^{\circ} 47$. Segundo cuatrimestre de 2021. Pp. 21-45. ISSN 1575-6823 e-ISSN 2340-2199 https://dx.doi.org/10.12795/araucaria.2021.i47.02 
natione Hispanus Tarraconensis, puesto que en la propia inscripción señala que fue realizada estando él vivo. Al igual que en la primera inscripción de Diocles, donde se le identifica como natione Hispanus Lusitanus, nos resulta difícil de interpretar el término natione Hispanus Tarraconensis. No queda claro si se refiere a su origen hispano, al que se añade la precisión de haber nacido en la provincia con capital en Tarraco, o si en vez de la provincia se refiere a la propia ciudad de Tarraco. Ninguna de las dos opciones parece contar con más peso que la otra ${ }^{23}$.

\section{Inscripción procedente de Nemausus (Gallia Narbonensis) ${ }^{24}$.}

/ T(h)r(aeci) / Q(uinto) Vettio Graci/li cor(onarum) trium / annorum XXX / natione Hispan(o) / donavit L(ucius) Sestius / Latinus / d(octor)

Quintus Vettius Gracilis es otro gladiador que falleció con 30 años y que se identifica con las palabras natione Hispanus. Como hemos mencionado anteriormente, la referencia al origen está en relación con su identidad a la hora de luchar en la arena. La inscripción fue dedicada por Lucius Sestius Latinus, su doctor, o entrenador personal (Bomgardner 2000: 115).

Podemos extraer algunas conclusiones sobre este conjunto de inscripciones ${ }^{25}$. No es extraño que todas salvo una procedan de territorios de fuera de la península Ibérica. La identificación mediante la natio toma sentido en los lugares en los que esa característica queda bien delimitada frente a la mayoría. El único caso procedente de Hispania, de Corduba $\left(\mathrm{n}^{\mathrm{o}} 7\right)$, hace mención a su natio hispana, al tratarse de un dato importante para un gladiador.

Los cuatro hispanos cuya edad es recogida en los epitafios contaban con $30\left(n^{\circ} 9\right), 40\left(n^{\circ} 1\right), 60\left(n^{\circ} 5\right)$ y 81 años $\left(n^{\circ} 8\right)$, mientras que la inscripción de Diocles señala que se retiró a los $42\left(n^{\circ} 3\right)$. Se trata, por tanto, de cinco adultos, dos de los cuales superarían la esperanza media de vida en la época. No se conservan inscripciones de niños o jóvenes de los que se haga notar su natio hispana.

De los ocho personajes que se identifican natione Hispanus/a, las inscripciones de cuatro de ellos se hallaron en Roma e Italia ( $\left.n^{\circ} 1-5\right)$, una en Hispania $\left(n^{\circ} 6\right)$ y tres en otras provincias $\left(n^{0} 7-9\right)$.

En cuanto a la identificación de los personajes, tres $\left(n^{\circ} 5,7\right.$ y 8$)$ fueron soldados del siglo II d.C. que terminaron viviendo en las provincias de Moesia superior, Pannonia superior y en Italia. La mención a su origen resulta lógica puesto que querían identificarse en su lugar de residencia, allí donde eran una minoría. Cuatro de las 9 inscripciones hacen referencia a personajes

\footnotetext{
${ }^{23}$ Ortiz Córdoba (2019: 81) lo identifica como natural de Tarraco.

${ }^{24}$ CIL XII 3332= ILS 5087=AE 1962, 62.

25 Estas conclusiones no se extraen sobre aquellos que se identifican como hispanos, sino sobre aquellos que optan por la fórmula natione Hispanus/a, que resultan una minoría del total.
} 
relacionados con juegos públicos: un auriga (Diocles, con las inscripciones $\mathrm{n}^{\circ} 3$ y 4) y dos gladiadores (inscripciones $n^{\circ} 6$ y 9 ). El origen de los protagonistas de los espectáculos de masas son uno de los elementos distintivos que los definen. Desconocemos las ocupaciones de $\operatorname{los} \operatorname{casos} \mathrm{n}^{\mathrm{o}} 1$ y 2 , ambos procedentes de Roma.

El término natio es utilizado por los hispanos también para señalar otros niveles de procedencia. A nivel intermedio encontramos a Atilia, de los siglos I-II, que se identifica natione Callaeca (CIL VI, 39696), en referencia al territorio de Callaecia formado por los conventos jurídicos lucense y bracaraugustano. Más abundante es el uso de natio para señalar el origen del municipium de origen. Marco Ulpio Aracinto, gladiador retiario, que alcanzó el culmen de la carrera gladiatoria, se identifica como hispanus (CIL VI 10184). A continuación, menciona que llegó a la categoría de palus primus, para finalmente añadir que su origen es natione Palantinus en referencia a Palantia (Hispania citerior) $^{26}$. Otros casos son el de Regina Titula, del s. III d.C., natione Arava (en Lusitania) (CIL VI 3422), Smaragido, natione Gaditano (AE 1908, 222) o Corbulo, natione Tarracone (AE 1992, 155.

\section{Reflexión final}

Hablar sobre Hispania como concepto y como natio no es tarea fácil. El historiador, como ciudadano del s. XXI, encuentra dificultades a la hora de prescindir de las implicaciones que tiene el término nación en nuestros días. Y debe hacer abstracción de la enorme carga que supone la proyección hacia el pasado de su visión de la realidad actual. La tradición historiográfica española desde los Reyes Católicos ha defendido la existencia de los españoles como entidad con rasgos propios de forma lineal y continuada, de manera que los valores de los españoles modernos habrían sido los mismos que los de los defensores de Numancia (Wulff Alonso 2000: 185ss., cf. n. 2 para más bibliografía). Por el contrario, algunos autores actuales, con el fin de rebatir estas ideas, se han ubicado en el extremo opuesto, llegando a afirmar que el vocablo Hispania tenía contenido exclusivamente geográfico ${ }^{27}$. Julio Caro

\footnotetext{
${ }^{26}$ En opinión de Gómez Pantoja, Hispanus "no es el etnónimo del gladiador, sino la referencia al ludus de origen o al particular modus pugnandi del difunto" (Gómez-Pantoja 2006: 175)

27 Por tomar un ejemplo de esta tendencia, Álvarez Junco señala que "terminada, al final de ese período, la conquista de la Península por César y Octavio, durante los cinco siglos siguientes se completó su incorporación al mundo romano (...). Pasó ese medio milenio sin que destacaran signos dignos de mención de una personalidad 'hispana' peculiar en relación con las demás provincias romanas. No sólo seguía sin haber existido hasta el momento una unidad política que englobase a la península Ibérica en su conjunto, sino que ni siquiera se había establecido nunca una unidad administrativa, una provincia del Imperio, que respondiera al nombre de 'Hispania"' (Álvarez Junco 2001: 37).
} 
Baroja, en su obra El mito del carácter nacional desacredita de forma clara la existencia de un mismo carácter hispano o español desde época prerromana. Pero el autor alerta del error de ambas posturas y denuncia que junto a los que atribuyen el carácter nacional a todas las épocas, ha aparecido otra tendencia que destruye toda interpretación sobre el origen y modo de ser de los habitantes de la península. Sobre este aspecto, quisiera traer aquí sus palabras: "Se nos dice asimismo (como si esto fuera un descubrimiento sensacional) que los iberos no eran españoles, que tampoco lo fueron los hispano-romanos, ni los visigodos: que no llega a haber españoles más que a raíz de ciertos conflictos de tipo racial y religioso (...). Nadie duda de que los iberos no fueron españoles; pero historiadores, antropólogos, etc. han aceptado una herencia ibérica y, más aún, una herencia hispano-romana, otra visigótica, otra islámica, etc., etc. Estas herencias son, por otro lado, diferentes en cantidad y calidad en las distintas partes de la Península, y sus proporciones, muy variables, hacen que a veces lo que es fundamental para la vida del español del Mediodía sea casi irrelevante para el Norte, dentro de este acervo de bienes y de males heredados. Querámoslo o no, hay también otro hecho evidente, que es el de que desde que se escriben los primeros tratados, con ciertas pretensiones científicas, acerca de la Geografía del antiguo mundo, la entidad geográfica llamada Hispania o Iberia se halla utilizada del mismo modo como se usan las de Galia, Britannia, Italia o Hélade" (Caro Baroja 2004: 36-37)

Resulta indudable que al menos una parte de la España actual mantiene algo de la herencia recibida de la Hispania romana. Se pone a menudo el ejemplo del idioma, el derecho o la religión. No es una herencia directa, ni homogénea ni igualmente apreciada. También es difícilmente cuantificable, especialmente si entramos en aspectos como la identidad o la personalidad. Pero en ocasiones encontramos datos concretos que nos traen esa herencia a la actualidad. En el año 1984 se localizó en el paso de Panissars (Departamento de los Pirineos Orientales, Francia) el trofeo que Pompeyo erigió en el lugar que marcaba el límite de Hispania en el extremo oriental de los Pirineos. La Universidad de Perpignan inició un proyecto de excavación del mismo, y la sorpresa fue grande cuando, al hacer la medición de las coordenadas en las que se encontraba, el monumento se hallaba situado en la línea misma de la frontera actual entre Francia y España. Esta circunstancia obligó a crear un equipo paralelo español que excavase la parte española. Ambos equipos conformaron finalmente un equipo hispano-francés que publicó las excelentes conclusiones del proyecto (Castelvi, Nolla, y Roda 2008). Nuestra herencia recibida en esta frontera es literal. La línea fronteriza entre hispanos y galos durante la antigüedad, surgida de una decisión de Pompeyo en el 73/71 a.C., afecta directamente a la administración diplomática de finales del siglo XX y principios del XXI. No hay motivos para pensar que esta herencia no existe 
también, como afirmaba Caro Baroja, en otros aspectos menos tangibles del acervo de bienes y de males heredados.

En este artículo hemos visto cómo Hispania y los hispani fueron una creación de Roma que afectó a toda la variedad de pobladores de la península. Muchos de éstos asimilaron y utilizaron el concepto para identificarse ante romanos, itálicos y otros pueblos semejantes a ellos. Su origen geográfico, junto con unas características físicas y culturales generales, era lo que les definió. Los hispanos eran identificados como tales a la hora de servir como esclavos, luchar en la arena, correr en las carreras, combatir en el ejército, comerciar, escribir literatura y filosofía, ejercer la política o hasta regir el Imperio. La forma en que esta identidad propia y ajena fue adoptada por los hispanos fue, sin duda, muy desigual. Mientras que en algunos casos no parece ir más allá de indicar el lugar de nacimiento, en otros tuvo un componente afectivo bastante marcado.

En este contexto se utilizó el término natio. Su complejidad contrasta con la libertad con la que se utilizó la palabra. Tanto las fuentes literarias como las epigráficas lo usan para indicar procedencia y pertenencia a la comunidad de una ciudad, región, provincia o a un pueblo en el sentido amplio de la palabra. Pero también para indicar unas características físicas y culturales o trasladar la personalidad en la lucha en la arena o en las carreras del circo. El término natione Hispanus lo utilizan los soldados que se quedan a vivir en el extranjero, aurigas y gladiadores y emigrantes hispanos en Roma.

Finalmente, cabe preguntarse si Roma pudo percibir como un peligro que los Hispani se reconociesen como tales. Un grupo amplio de indígenas que sufrió una dura y larga conquista podría guardar resentimiento contra su dominador y deseos de recuperar la antigua libertad. Ejemplos de este tipo no faltan, algunos incluso terminaron en rebeliones como la guerra judaica y el posterior levantamiento de Bar Kojba. No existe el más mínimo indicio de algo parecido que afecte a los hispani en su conjunto. Ser hispano no entraba en conflicto con otras identidades, ni generó ninguna resistencia común, ni reavivó antiguas afrentas de la época de la conquista. Como afirma Floro, Hispania no tuvo conciencia de sí misma hasta que fue sometida. Este descubrimiento, el ser hispano, fue la forma que estableció Roma para integrar a una gran masa heterogénea de población en el territorio romano. La identidad hispana, por tanto, lejos de servir para distanciarse de Roma, fue el instrumento eficaz de ésta para integrar a los hispanos en el Imperio romano. 


\section{Bibliografía:}

J. N. Adams, The regional diversification of Latin $200 B C-A D$ 600, New York, Cambridge University Press, 2007.

G. Alföldy, "Hadrians Besuch in Tarraco" en C. Bertrand-Dagenbach y F. Chausson (eds.), Historia Augusta. Colloquium Nanceiense. Atti dei Convegni sulla Histora Augusta XII, Bari, 2014, pp. 11-29.

G. Alföldy, "Zu den Monumenten der römischen Provinzen auf dem Augustusforum" en H.J. Drexhage y J. Sünskes (eds.), Migratio et commutatio. Studien zur Alten Geschichte und deren Nachleben. Thomas Pekáry zum 60. Geburtstag am 13. September 1989 dargebracht von Freunden, Kollegen und Schülern, St. Katharinen, Scripta Mercaturae Verlag, 1989, pp. 226-234.

G. Alföldy, "Zur Präsenz hispanischer Senatoren in Rom: Ehrenund Grabmonumente aus der Hohen Kaiserzeit" en AA.VV., De Augusto a Trajano: un siglo en la historia de Hispania, Pamplona, EUNSA, 2001, pp. 69-92.

F. Álvarez Junco, Mater Dolorosa. La idea de España en el siglo XIX, Barcelona, Taurus Historia, 2001.

F. Beltrán Lloris, “... «Et sola omnium provinciarum uires suas postquam uicta est intellexit». Una aproximación a Hispania como referente identitario en el mundo romano", en A. Caballos Rufino and S. Lefebvre (coords.), Roma generadora de identidades. La experiencia hispana, Madrid, Collection de la Casa de Velázquez y Universidad de Sevilla, 2011, pp. 55-77.

F. Blanco Robles, "De Iberia a Hispania: la formación de una identidad en la Antigüedad (I)”, Hispania Antiqva. Revista de Historia Antigua, 44 (2020), pp. 316-338.

J.M. Blázquez Martínez, "El nombre de Hispania aparece en la historia. Los hispanos en el Imperio Romano", en V. Palacio Atard (ed.), De Hispania a España. El nombre y el concepto a través de los siglos, Madrid, Ed. Temas de Hoy, 2005 pp. 17-39.

D.L. Bomgardner, The Story of the Roman Amphitheatre, Oxford, Routledge, 2000.

F. des Boscs-Plateaux, Un parti hispanique à Rome? Ascension des élites hispaniques et pouvoir politique d'Auguste à Hadrien (27 av. J.-C.-138 ap. J.-C.), Madrid, Bibliothèque de la Casa de Velázquez, 2005.

A. Caballos Rufino, Los senadores hispanorromanos y la romanizacion de Hispania (siglos I al III p. C.). I. Prosopograffa, Écija, Monografías del Departamento de Historia Antigua de la Universidad de Sevilla, 1990.

A. Caballos Rufino y S. Lefebvre, Roma generadora de identidades. La experiencia hispana, Madrid, Casa de Velázquez, 2011.

M.C. Caltabiano, "Sulla cronología e la metrologia delle serie Hispanorum", Numismatica e Antichità Classiche, 14 (1985), pp. 159-169.

J. Caro Baroja, El Mito Del Carácter Nacional, Madrid, Ed. Caro Raggio, 2004.

A. Cascón Dorado, "Affectus Hispaniae en la historiografía del Alto Imperio" Gerión 35 (2017), pp. 41-60.

G. Castelvi, J. M. Nolla, e I. Roda, Le Trophée de Pompée Dans Les Pyrénées. Paris, 2008.

A. Ceballos Hornero, "Epitafios latinos de gladiadores en el Occidente romano", Veleia, 20 (2003), pp. 315-330.

G. Cruz Andreotti y B. Mora Serrano (eds.), Identidades étnicas - identidades politicas en el mundo prerromano hispano, Málaga, Publicaciones Universidad de Málaga, 2004. 
J.L. Cunchillos, "Nueva etimología de la palabra "Hispania", en M. Aubet Semmler y M.E. Barthélemy (coords.), Actas del IV Congreso Internacional de Estudios Fenicios y Púnicos: Cádiz, 2 al 6 de octubre de 1995, Cádiz, 2000, 217-225.

J.L. Gómez-Pantoja, Epigrafia Anfiteatrale Dell'Occidente Romano. VII Baetica, Tarraconensis, Lusitania, Roma, 2009.

M.C. de la Escosura Balbás, "Diocles. Lo Sportivo Più Pagato Della Storia." Forma Vrbis, 17.4 (2012), pp. 30-35.

M.C. de la Escosura Balbás, "Documenting Hispanic Immigrants in Italia, Gallia, and Britannia." En C.F. Noreña y N. Papazarkadas (eds.), From Document to History. Epigraphic Insights into the Greco-Roman World, Leiden, 2019, pp. 326-355.

M. Díaz-Andreu, et al., The Archaeology of Identity. Approaches to Gender, Age, Status, Ethnicity and Religion, London, Routledge, 2005.

A.J. Domínguez Monedero, "Los términos "Iberia" e "Iberos" en las fuentes grecolatinas: estudio acerca de su origen y ámbito de aplicación”, Lucentum, 2 (1983), pp. 203224.

A. García y Bellido, "El español Diocles, "as" de los circos romanos”, Arbor, 32 (1955), pp. 252-262.

F.J. Gómez Espelosín et al., La imagen de España en la Antigüedad clásica, Madrid, Ed. Gredos, 1995.

J.L. Gómez-Pantoja, "Entre Italia e Hispania: los gladiadores", en A. Sartori y A. Valvo (eds.), Hiberia-Italia, Italia-Hiberia, Milano, 2006, pp. 167-180.

S. Kočovska-Stevović, "On the Roman Concept of Natio" Colloquia Humanistica, 5 (2016), pp. 3-18.

S. Lefebvre, "Onomastique et identité provinciale. Le cas de "Lusitanus", en A. Caballos Rufino y S. Lefebvre, Roma generadora de identidades. La experiencia hispana, Madrid, Casa de Velázquez y Universidad de Sevilla, 2011, pp. 153-170.

Mangas Manjarrés, J., and M.M. Myro. Testimonia Hispaniae Antiqua III. Medio físico y recursos naturales de la Península Ibérica en la antigüedad. Madrid: Ed. Complutense, 2003.

J. Mangas Manjarrés y S. Montero Herrero, Ciudadanos y extranjeros en el mundo antiguo. Segregación e integración, Madrid, Ediciones 2007, 2007.

G.A. Mansuelli, Le stele romane del territorio Ravennate e del Basso Po, Ravenna, Collana di studi d'arte paleocristiana, bizantina ed altomedievale, 1967.

N. Méthy, "La representation des provinces dans le mennayage romain de l'époque impériale (70-235 après J.-C.)", Numismatica e Antichità Classiche, 21 (1992), pp. 267-289.

J. Ortiz Córdoba, "Reclutamiento y unidades militares en las colonias romanas de la Hispania citerior”, Gladius, 39 (2019), pp. 71-91.

P. Ozcáriz Gil, "Los iuridici de la provincia Hispania citerior: cuestiones acerca de su origen y naturaleza", Espacio, Tiempo y Forma, Serie II, Historia Antigua, 19-20 (2006-2007), pp. 525-533.

P. Ozcáriz Gil, La administración de la provincia Hispania Citerior durante el Alto Imperio romano, Barcelona, Serie Instrumenta. Universitat de Barcelona, 2013.

D. Plácido Suárez, "La imagen simbólica de la Península Ibérica en la Antigüedad”, Studia Historica. Historia Antigua, 13-14 (1995-6), pp. 21-37.

C. Ricci, "Hispani a Roma”, Gerión, 10 (1992), pp. 103-143. 
J.M. Roldán, Hispania y el ejército romano: contribución a la historia social de la España antigua, Salamanca, Universidad de Salamanca, 1974.

P. Le Roux, L'armée romaine et l'organisation des provinces ibériques d'Auguste a l'invasion de 409, Paris, Diffusion de Boccard, 1982.

A. Schulten, "El nombre "España", Investigación y Progreso, 8.6 (1934), pp. 161-163.

M. Sordi, "La Spagna nel Panegirico di Plinio e in quello di Pacato" en G. Urso (ed.), Hispania terris omnibus felicior. Premesse ed esiti di un processo di integrazione, Pisa: Edizioni ETS, 2002, pp. 315-322.

P.P. Spranger, "Die Namengebung der römischen Provinz Hispania", Madrider Mitteilungen, 1 (1960), pp. 122-141.

F.W. Walbank, "Nationality as a Factor in Roman History", Harvard Studies in Classical Philology, 76 (1972), pp. 145-168.

F. Wulff Alonso, "Nacionalismo, Historia, Historia Antigua: Sabino Arana (1865-1903), la fundación del nacionalismo vasco y el uso del modelo historiográfico español", Dialogues d'Histoire Ancienne, 26.2 (2000), pp. 183-211.

G. Zernatto, "Nation: The History of a Word", The Review of Politics, 3 (1944) pp. 351366. 
